\title{
Powerplay in
}

\section{Nigerian Political Visual Discourse:}

Profiling the All Progressives Congress Party

\author{
Kunle Oparinde \\ Maleshoane Rapeane-Mathonsi \\ Gift Mheta
}

\section{Abstract}

The discourse of politics is believed to be dominated by manipulative rhetoric. In this paper, we analyse and discuss the tactical use of discourse resulting in powerplay by the All Progressives Congress (henceforth APC) political party in Nigeria. This is done from a Multimodal Discourse Analysis (MDA) perspective, using the re-contextualisation theoretical model for analysing misrepresentation and manipulation in political discourse. The paper unravels how the APC employs political discourse to exert influence on the masses. Along with support from other linguistic items, the study discovered that the APC are skilful in selecting specific visual and lexical items to achieve their political communication. Thus, this study exposes cases of political artifice as employed by the APC. In total, eleven (11) APC campaign materials were analysed using a purposive sampling method. The paper further confirms the hitherto-stated proposition that discursive strategies are essential in political campaigns and are in some cases employed to attract mass support from the electorate.

Keywords: discourse, politics, communication, visuals, lexis 


\section{Introduction}

This research studies powerplay as used by the APC in political discourse in Nigerian political settings. Political discourse is considered to be a type of discourse based on views and beliefs, the purpose of which is to manipulate the consciousness of the addressee using strategies in order to shape certain beliefs (Chikileva 2018: 20). Lirola (2016: 263) asserts that multimodal text is a powerful tool used in election campaigns to persuade people to vote, and to convince them of the convenience of choosing the candidate proposed by the way this text is constructed visually. In this light, Ademilokun (2016) observes that political discourse occupies a strategic space, as it is not a mere adventure, but often has serious political implications; hence, making it worthy of academic investigation.

Davletbaeva et al. (2016: 242) note that politicians use several devices to achieve actual political aims through various kinds of persuasion. They further maintain that politicians employ effective image-making strategies through visual means. The creation of effective visual tools for persuasion (political advertisements and cartoons) allow politicians to introduce socially relevant and culturally oriented concepts for the purpose of maintaining their power and reinforcing their serious impact on public opinion. In the same vein, Mocanu (2015) argues that political communication is expressed through extremely varied means, such as images, music, objects, uniforms and symbols.

Ademilokun and Olateju (2015: 1) explain that semiotic resources or artefacts are an important aspect of political campaigns because of the inherent political, cultural and social communication revealed through them. Elebute (2013: 264) affirms that excellent symbolic design of visuals has endowed the political landscape of Nigeria with manifold opportunities to recognise the essence of promoting politicians.

It is in keeping with the above tenets that this study, through the use of multimodal discourse analysis (MDA), investigates powerplay in the use of political visual discourse, as exemplified by the APC.

\section{Conceptual Perspectives and Analytical Model}

For this study, a conceptual framework which appraises visual elements in discourse, MDA, is employed to analyse powerplay as used by the APC. As 
defined by Jones (2012: 52), MDA focuses on how meaning is made through the use of multiple modes of communication, as opposed to just language. For Machin (2007), MDA is a social semiotic approach to visual communication which provides a tool for the analysis of visual compositions, such as advertisements, magazine covers or pages, and photographs. Hence, the method allows us to break down compositions into their basic components in order to understand how they work together to create meaning. Kress and van Leeuwen (1996: 183) state that multimodal discourse takes place when meaning is realised through more than one semiotic code. Thus, a multimodal analyst is interested in how the products of these various codes are analysed in an integrated way. The analyst is further interested in the interactions between different semiotic systems, and also how these systems affect one another (Cameron and Panovic, 2014).

Seen from another perspective, Li (2016: 934) states that MDA,

adopts the view that diverse semiotic modes (e.g. language, images, music, sound, animation, and so on) are combined together to multiply the meaning in multimodal texts or communicative events.

While multimodality in discourse is seen by van Leeuwen (2005: 28) as the 'combination of different semiotic modes such as in a communicative artefact or event', Liu (2013: 1259) stipulates that multimodality refers to the

diverse ways in which several distinct semiotic resources are codeveloped and co-contextualised in the making of a text-specific meaning.

Using Norris' (2016) opinion that the overall importance of MDA not only concerns meaning-making resources, but also the society and roles of discourse users, we illustrate instances of visual modes of communication in Nigerian political discourse with close reference to the user and society. This creates a strong link between MDA and the theoretical model proposed by Oparinde (2018) for analysing discursive misrepresentation and manipulation. Oparinde's framework associates situational context with discourse as a way of ensuring that discourses are examined alongside contextual factors. Oparinde's framework is articulated in Figure 1. 


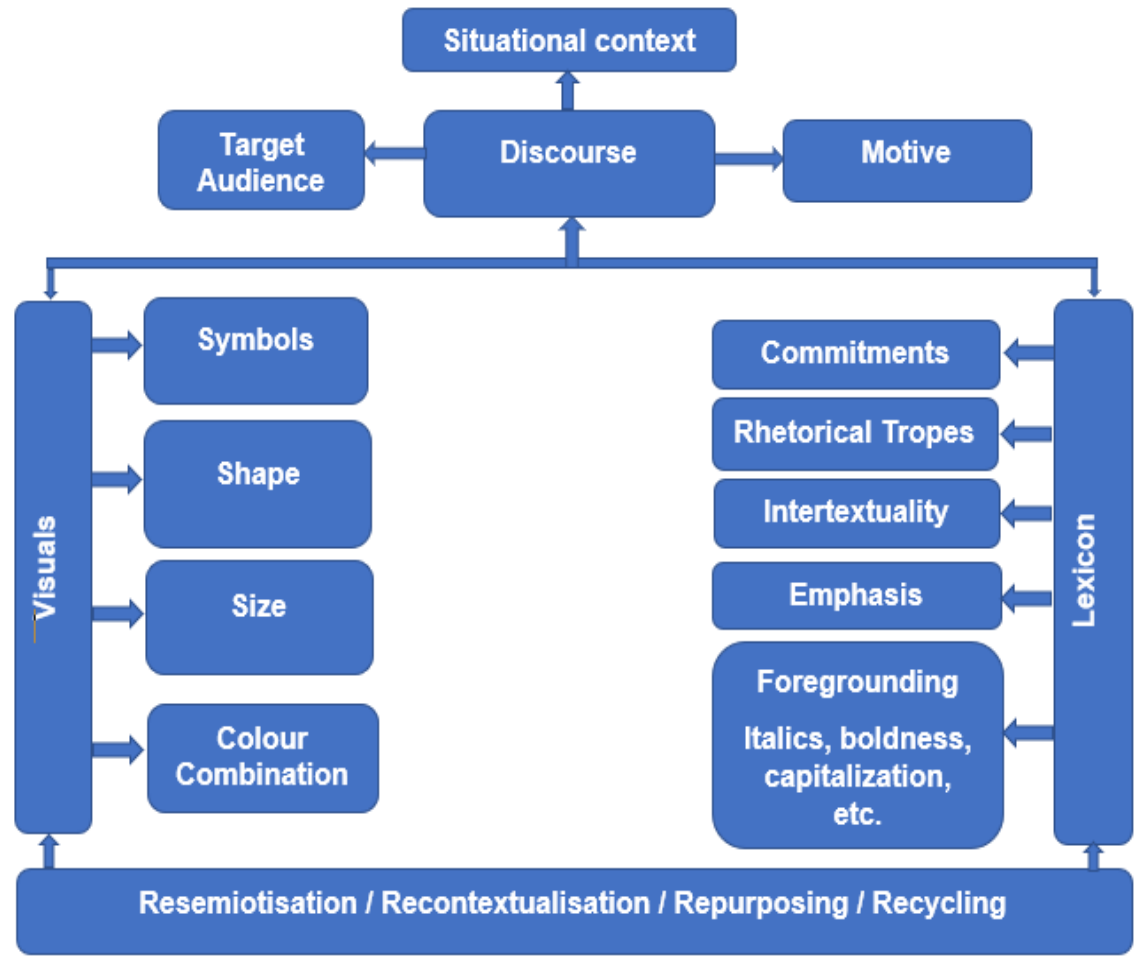

\section{Figure 1: A Theoretical Model for Analysing Misrepresentation and Manipulation in Discourse}

Discourses can be visual or lexical. At a visual level, the communicator pays attention to details by being cognisant of what could appeal to an audience. The colour, size, symbols and shapes which best represent the discourse are carefully chosen in political discourse. Since the aim of political discourse is to persuade and play on the emotions of electorates, politicians attempt to influence the vision of an audience, to select the appropriate visuals. This study contends that discourses are not free of value; rather, discourses are often embedded with conceptions an audience may be less conscious of. This is a point that was earlier acknowledged by Foucault (1972) suggesting that for every communication, there is an ideological stance, or distinction, with the ideology of a speaker also contributing to manipulation. In agreement with this, 
Beard (2000: 18) stipulates that language is not separate from the ideas it contains, but the way language is used says a great deal about how its ideas have been shaped.

In the theoretical model of Oparinde (2018), 'discourse' is the common thread. However, for discourse to function and perhaps exert influence, different linguistic dynamics are employed. The situational context is also important in this model. To analyse powerplay in political discourse, there is a need to understand the context for which the discourse is developed. There may be several contexts, such as religious, political, academic, ethnic, and so on. Such contexts dictate how language is used, and what choice of words is employed by the speaker.

Lexicons, referring to the choice of words employed in communication, are strong features of linguistic manipulation. Political discourses are littered with carefully selected or specifically chosen words to achieve political objectives. Additionally, certain parts of messages are deliberately foregrounded (italicised, bold or capitalised) by the user of the discourse to achieve certain objectives. A closer analysis of these linguistic devices may reveal a degree of manipulation and misrepresentation in this type of discourse.

Oparinde's (2018) model, as well as MDA, recognise both visuals as well as the use of lexical items as a means of communication. In most cases, visuals are not presented in isolation but are often accompanied by linguistic items. Saddled with the responsibility of accentuating or emphasising the visual elements, the use of these lexical items results in the visual elements becoming less hindered when used alongside words. Thus, the fusion of MDA and Oparinde's model provides a comprehensive framework for analysis and interpretation of political discourse. Hernández-Guerra's (2013: 59) postulates that political discourse study is a discipline which reveals more information than a first reading can offer. Blended analytical frameworks might also better enable an understanding of political materials.

\section{An Overview of the All Progressives Congress}

Here we present an abridged historical overview of the APC adopted from their website. APC - http://apc.com.ng/about-apc/:

The All Progressives Congress (APC) is a political party in Nigeria formed in February 2013 which was in preparation for the 2015 
nationwide elections. The party is the result of a merger of Nigeria's three biggest opposition parties - the Action Congress of Nigeria (ACN), the Congress for Progressive Change (CPC), the All Nigeria Peoples Party (ANPP) - and a faction of the All Progressives Grand Alliance (APGA). In the resulting election, the party's candidate, Muhammadu Buhari won the presidential election by almost 2.6 million votes defeating the incumbent President Goodluck Jonathan. The election was recorded as the the first time in Nigeria's political history where an opposition political party displaced a governing party in a general election and one in which power was transferred peacefully. The party also won most seats in the Senate and the House of Representatives in the same year.

\section{Methodology}

This study employed a qualitative research methodology in examining powerplay in political discourse, specifically as it relates to the APC, which is the current ruling party in Nigeria. Purposive sampling was used to collect materials from billboards, newspapers and posters. This study focused on discourses in English, the official language in Nigeria. Materials used for political promotion in the federation of Nigeria were selected for analyses and included materials from 2010 leading up to the 2011 general elections, as well as leading up to the 2015 general elections. The choice of materials was informed by its accessibility by the electorate and digital media was excluded given limited connectivity by a wide audience. Eleven (11) artefacts of visual materials were analysed and have been classified thematically.

\section{Powerplay in the Political Discourse of the APC}

The analyses of the visual electioneering materials employed by the APC during general elections in Nigeria are presented below.

\section{Symbolising the Redemption of Service Delivery}

One of the foremost perceived criticisms of the administration of President Goodluck Jonathan (former President of Nigeria of the People's Democratic Party (PDP)) was the non-delivery of relevant civic services. As such, a large 
percentage of APC electioneering material dwells on the redemption of the delivery of essential services, such as electricity which was almost non-existent during the regime of President Goodluck Jonathan. This is evident from the grouping of materials shown below, which are intended to depict the readiness of the APC to rehabilitate the country's dilapidated service delivery systems.
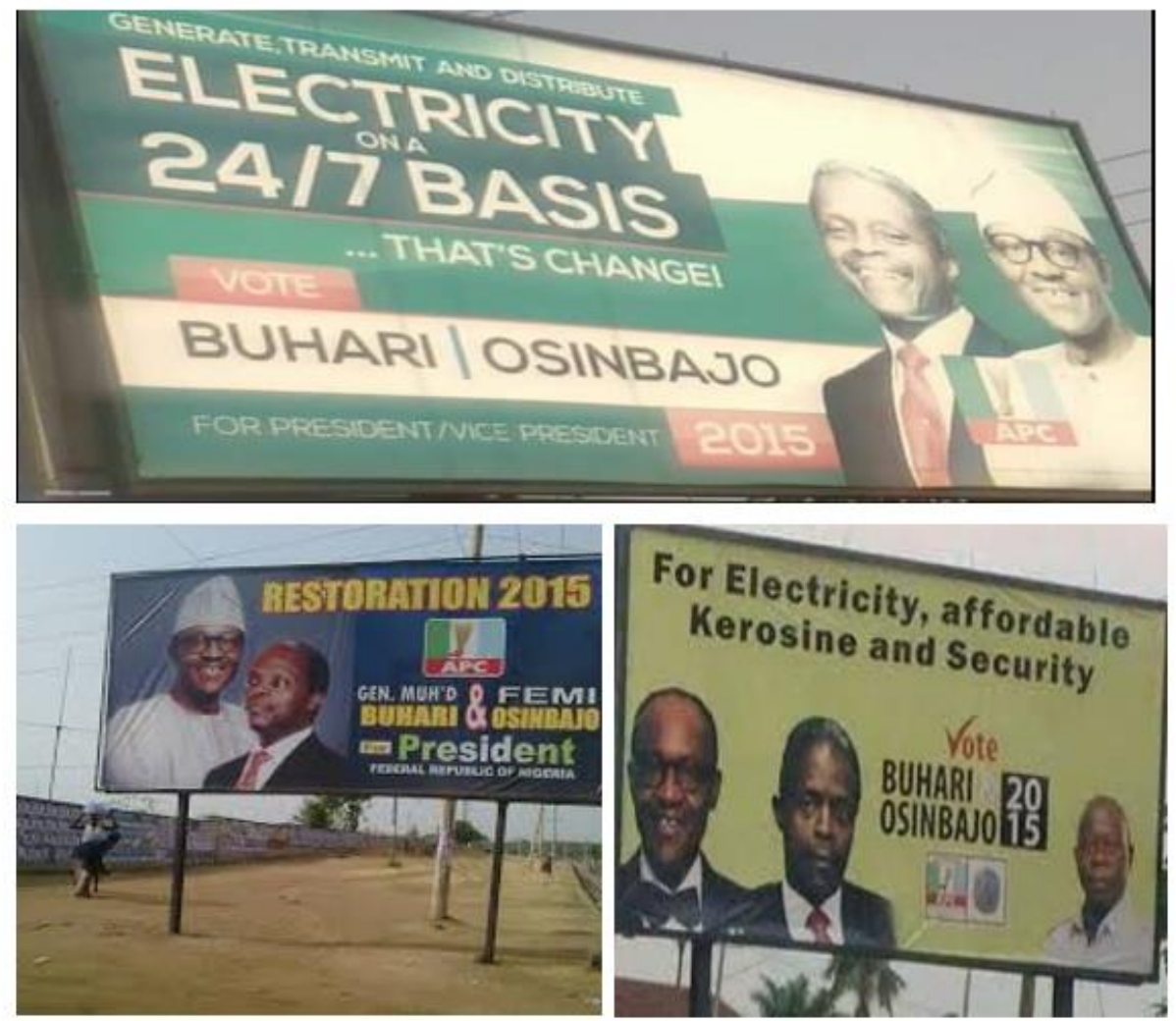

Figures 2, 3, 4: Presenting the symbolism of the redemption of service delivery

In one of the messages (Figure 2) titled 'Generate, Transmit and Distribute', it is implied that the APC intends to initiate the process of ensuring stable electricity supply, which was not present during previous administrations. As such, the APC now aspires to focus on transmitting and 
distributing energy effectively to the Nigerian population. For researchers, this creates an impression that the APC administration will attempt to make life comfortable for Nigerians. This is indeed a welcome campaign strategy for the Nigerian populace, especially as the message promises to revive the deteriorated condition of electricity in the country. The dilapidated state of electricity delivery in Nigeria has been a problem for decades. Paul, Albert and Adeiza (2015: 180) also note that 'the greatest engineering challenge in Nigeria today is the issue of the provision of steady, adequate, affordable and efficient electricity supply'. It is thus anticipated that politicians will capitalise on such societal issues in their political communications.

In this regard, the statement 'Electricity on a 24/7 Basis' (Figure 2) aptly expresses the impending or desired situation in Nigeria. This may in fact be considered an act of aggrandisement, in line with the context of critical discourse analysis (CDA), as the situation has permeated Nigerian society for a considerable length of time, and hence may not be resolved overnight. The parlance '24/7' implies the provision of electricity in Nigeria as being a '24 hours a day, and 7 days a week' phenomenon. As such, not only would citizens now begin to enjoy steady electricity, but they will also enjoy an uninterrupted supply of electricity. As Davletbaeva et al. (2016: 243) articulates it, political statements are permeated with messages which might cause the electorate to make assumptions and draw deductions from electioneering materials, regardless of whether these statements are entirely truthful.

Additionally, the use of the term ' $24 / 7$ ' was originally intended to represent days of the week, but it has been re-contextualised to mean 'constant'. It is important to note that Nigerian politicians are familiar with their environment, and as such use lexical choices which electorates can relate to. Re-contextualisation often implies a change of meaning from one context to another. Hence, Bakhtin (1986) notes that re-contextualisation occurs when texts or signs are extracted from one context to fit into another context for effective communicative purposes in what he refers to as 'intertextuality'. Bakhtin is of the view that there is no 'original' text, and that by implication, every text depends on the existence of other texts. and one is thereby able to identify elements of a previous text in a new text. Roberts (2017: 62) admits that Bakhtin's notion of intertextuality is centred on meaning-making, suggesting that the knowledge of previous texts contributes to the construction of meaning overall.

We also find a strong pragmatic meaning in the slogan Restoration 
2015 ' (Figure 1). As the election was to take place in 2015, the APC used this term to promote the reconstruction of Nigeria from a seemingly impending condition. The APC portrays itself as a party which is ready to salvage the situation in the country by restoring past glories. The term 'restore' carries the power to convey a sense of rehabilitation in the minds of the electorate. Consequently, this is bound to create hopes for the party because of an expectation of restoration. This is an instance of image-marketing, as discussed by Cabrejas-Peñuelas (2015), where the party involved, in this case the APC, attempts to sell their image to an audience in a positive light.

In Figure 3, the message, For Electricity, affordable Kerosine and Security' addresses the most important needs of Nigerians. As with the earlier analyses, this statement also refers to the situation of service delivery in Nigeria. The exorbitant price of fuel (kerosene) and a lack of security are also national issues of concern in Nigeria.

The APC has, through these messages, succeeded in identifying certain lexical items and phrases they assumed would be highly instrumental in their election campaign as they relate to Nigerians' standard of living. The phrase 'Affordable Kerosine' (Figure 3) confirms that they are trying to target poor Nigerians, who perhaps consider kerosene unaffordable. This is conspicuous, as the word 'affordable' is not used in conjunction with electricity. The choice of words in the above materials speaks to those issues affecting the state of living conditions for Nigerians. This idea is supported by Tepavčević (2014: 94), who is of the view that the language of politics is marked by the use of specific lexical items, phrases and hidden linguistic messages, purposely selected with the particular aims of politicians.

Interestingly, the above electioneering materials show the party has completely avoided the use of personal pronouns such as 'I' or 'we'. In our understanding, this may be considered an attempt to absolve themselves from committing to their promises. Instead, they make strong statements which hold no particular person responsible. This is perhaps what Michira (2014) refers to when he argues that politicians make different statements with no real intent, as they sometimes believe they can win an audience over based merely on linguistic prowess and finesse.

The fact that President Buhari appears in the native attire of Yoruba society from the western part of Nigeria on two occasions, carries symbolic meaning. This may represent his departure from his military persona as Major General of the Army under the military regime from 1983-1985. His manner 
of dress may be a method of convincing the masses that he is now a proper civilian, like the majority of Nigerians, as he is now retired from the army. On the other hand, vice-president Osinbajo appears in a suit, which is English formal attire. This may also serve as representative of him being an academic, as he is a Professor of Law. The same dress code continues to appear in upcoming data. Ademilokun and Taiwo (2013) indicate that print media campaigns are carefully considered, as they are often based on historical and social issues that persuasively convey their messages.

In one of the posters, President Buhari's electoral partner appears to the fore. That may be considered as a way of affirming that President Buhari does not see himself as the sole participant during the elections. In other words, he respects and values his colleague. This is, however, contradicted by the order of names given in the same material. While President Buhari comes second in terms of the images, his name is stated first. In other material, there is an image included of governor Adams Oshiomole, who is widely believed to be a human rights activist due to his role in fighting for justice when he was leader of the National Labour Congress (NLC) in Nigeria. In a sense, the billboard shows courtesy to Adams Oshiomole insofar as people consider him an activist; by implication, he thus believes that President Buhari and Vice-President Osinbajo will serve Nigerians with integrity. The additional importance in these materials is their use of capitalisation and bold font types. Distinctly, the use of upper case and bold fonts are meant to command the attention of an audience. This resonates with Lazović's (2014) study that orthographic features such as capitalisation and bold print are employed to emphasise a point.

Other service delivery issues such as roads, water and garbage removal do not feature in the campaign material. The researchers presuppose this may largely be a result of Nigeria's poor service delivery overall, and politicians' need to select those issues considered by Nigerians as highest priority. It is in this regard that the APC advocates for 'change' in virtually all Nigerian sectors, as noted in the data presented below.

In these data, the concept of re-semiotisation takes a strong foothold. Hence, the ideas of re-semiotisation, repurposing and re-contextualisation drawn from the area of intertextuality only connote the ability to employ certain texts to function effectively on different terrains. These terms are concerned with how certain texts are developed from existing texts, and how the developed texts are used to build other texts. Given this position, it is important to understand that while certain texts are used in different domains, 
politicians not only borrow these texts to function in other contexts but the texts are also borrowed to achieve purposes different from their initial sources. Zulpha (2017: 64) explains that re-semiotisation provides the analytical means for tracing how semiotics translates from one end to the other as social processes unfold, by asking why these semiotics (rather than others) are mobilised to convey certain messages at certain times.

\section{A Portrayal of Trust and Integrity}

In the electioneering materials below, the APC attempts to influence the voting choices of the electorate by framing their campaign in the discourses of 'integrity' and 'trust'. The use of these terms is viewed as a farce only by some and politicians are often blamed for corruption. The advertisements, however, portray politicians as honest and trustworthy in an attempt to gain confidence from the voters that they will not act in the best interest of the electorate. Buhari is revered by many for leading a popular coup which rescued the economy from the grip of the corrupt politicians of the Second Republic (Ogbeidi 2012: 8). President Buhari, also one of the least affluent past Nigerian Presidents, opportunises on his history to posit himself as the face of integrity.
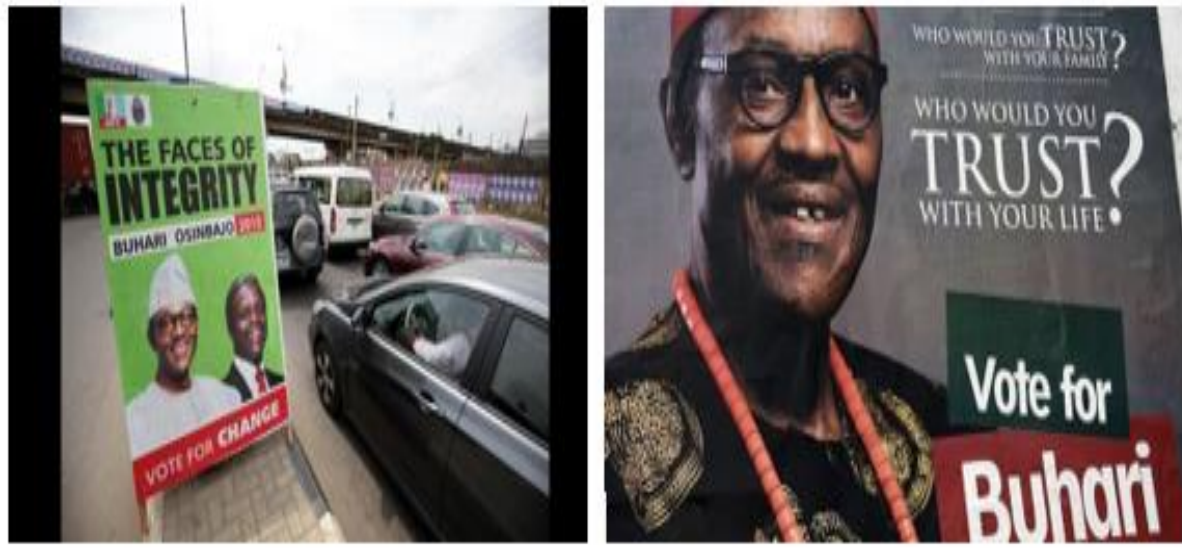

Figures 5, 6: Presenting the portrayal of trust by the APC

President Buhari is depicted with his vice president, Professor Osinbajo, a pastor. The portrayal of this union predicates the assumption that 
both leaders are trustworthy. This could perhaps be construed as a case of recycling the societal beliefs that the army is disciplined and that pastors can be trusted. These beliefs are thereby recycled and politically re-contextualised. Rose and Heywood (2013) advocate a need for political actors to have integrity in order for the people to trust them, have confidence in their actions, and consider them legitimate for political office. Despite the concept of 'integrity' being an important factor in politics, the field of political science has paid little attention to this construct in particular and political discourse in general.

The issue of 'integrity' in politics is not trivial; it explains why politicians employ such lexical items to achieve their political aims. The concepts of 'integrity' and 'trust' represent the quality or degree of honesty present, and also the presence of strong moral principles. The APC, following the maladministration of the country by the PDP, had to carefully choose certain linguistic expressions to denigrate the PDP, whilst using the same expressions to promote their own election campaign. It is likewise no coincidence that President Buhari's name is written in a white font colour (Figure 6). The colour white, particularly in Western culture, is associated with purity, transparency, cleanliness and safety, as well as peace, light, goodness and innocence, amongst other qualities. White is also associated with perfection. Semiotically. the colour, white, bears a positive connotation, and can also be perceived as promising of a prosperous new beginning for Nigeria should Buhari become president. This further explains why the lexis 'trust' is in white and bold, as is the case with Buhari's name.

President Buhari believes Nigerians will respect his integrity and trust him with their votes. Ike-Nwafor (2015) perceives this creative use of figurative expressions as strong weapons to influence voters. These expressions, as discussed, implicitly project both the image and political programme of the APC and President Buhari to voters. This is a strategy geared towards entreating people and appealing to the ideological senses of the masses. Essentially, such strategies are intended to control people's thoughts and perceptions, and manipulate unsuspecting members of the public into accepting the proposed candidacy (Emeka-Nwobia 2016: 12).

The texts entitled: 'Who would you trust with your family?' and, 'Who would you trust with your life?' are rhetorical questions with implied answers. In this regard Rigotti (2005) refers to the use of fallacies, or rhetorical devices, in political communication and notes that these are intentionally deployed to present a rational argument, while in fact being deceptive. This tactic, he 
argues, offers the advantage of having the appearance of good reasoning, while in reality being an attempt to silence opponents and persuade an audience of the reliability of a candidate's words. It is thus gathered from the above materials that politicians often draw attention to some attributes of an audience's character or society in order to make their audience believe their claims.

From a multimodal perspective, President Buhari again appeals to all sectors of Nigerian society in terms of its diversity, also appearing in attire common with the Igbos in the Eastern part of Nigeria (Figure 6). This is an attempt by the President to exhibit his universality as a citizen of Nigeria, thereby erasing the sensational or tribal perception that he only belongs to the North. The president has now appeared in the popular attire of the three major tribes in Nigeria, namely: Yoruba, Hausa and Igbo as a sign of his allegiance to all and not to a particular group or demographic area only.

\section{Corruption as a Menace in Nigeria}

One of the general issues permeating governance in Africa is corruption and Nigeria has also been perceived as having a corrupt government. An administration which pledges to address corruption may thereby appear attractive to the masses.

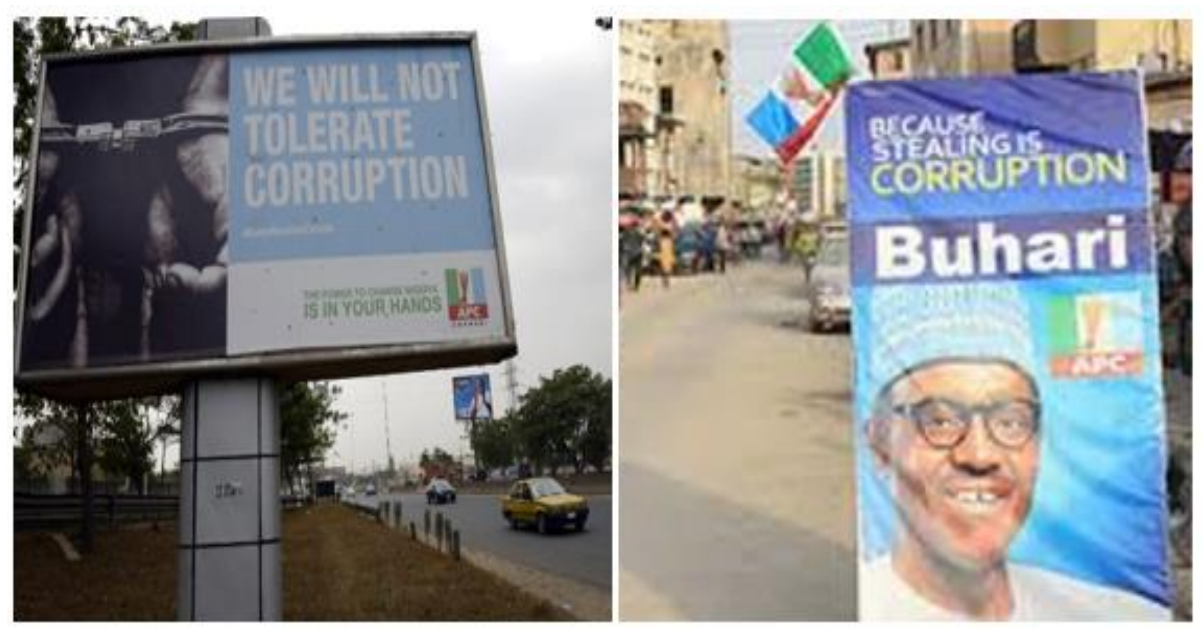

Figures 7, 8: Presenting the situation of corruption in Nigeria 
President Jonathan, the former president of Nigeria, has been seen as complicit in corruption with his unpopular statement that stealing from the government was not an act of corruption (Africa Check 2014). His statements present a great opportunity for the campaign strategy of the APC, who holds that contrary belief that the theft of public funds through the abuse of public office is a corruptive act.

The text 'We will not tolerate corruption' on the billboard depicted in figure 7 is in bold font. This again resonates with Elebute's (2013) appraisal of bold and gothic writing aimed at legibility, and the use of a robust form of writing which denotes elegance and fashionableness. The pronoun 'we' in the same sentence is intended to place the APC in a position of collective responsibility concerning the issue of corruption in Nigeria. However, the message in the political material is communicated in an evasive manner, as the lexical item 'we' is ambiguous and does not refer to anyone in particular. This may indeed be deemed as manipulative, and an escapist approach.

Maalej (2013) acknowledges the use of personal deixis in political communication. Maalej favours the use of 'I' over 'we', because the former refers to a specific subject that is capable of potentially taking responsibility. However, the latter is often deliberately employed by politicians to imply that responsibility does not rest solely with them as individuals, but includes the governing body, political party and the masses. Maalej considers the main function of such a pronoun to be emotional, appealing to the senses of an audience, and encouraging solidarity.

In another instance, the modal 'will' indicates the APC's intention to address corruption, even though this may only occur in the future. The verb emphasises the desired intention of the party to deal with the menace of corruption. Ehineni (2014), in his study of modals, notes that such verbs signify political will, commitment, promises and appeals, along with possibilities and persuasions, and also the making of pledges to the public by politicians. Such modals reinforce the political ideas of politicians, whilst simultaneously eliciting public support. Ehineni maintains that modals should not only be considered as linguistic elements, but most importantly as political devices and ideological tools within political discourse.

From an MDA perspective, President Buhari also appears as the only presentable candidate for the APC (Figure 8) creating the impression that he is the flag bearer of the party. A closer look at the word 'corruption' in the same material presents the lexical item in a different colour, namely yellow, which 
is more obvious and noticeable. In addition, Figure 7 visually depicts an arrested culprit (presumably a criminal of corruption) who has been handcuffed, which is intended to further maintain the intention of the party in rooting out corruption.

\section{An End to Insecurity}

The Boko Haram insurgency has, over the years, presented a significant security challenge in Nigeria. Consequently, Nigerians have continuously clamoured for the government to take a courageous step towards defeating the organisation. This explains why the APC places defeating Boko Haram as a top electioneering campaign priority and presents the lexical item 'defeat' in a large bold font (Figure 9).
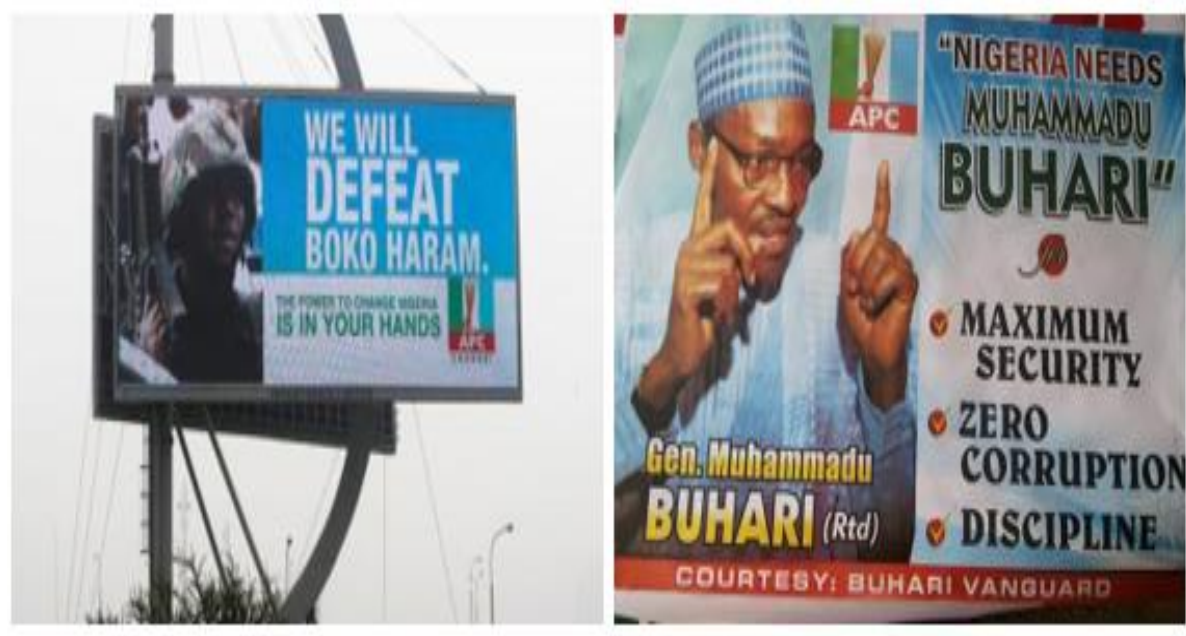

Figures 9, 10: Presenting an end to insecurity in Nigeria

The effect of bold writing, the pronoun 'we', and the verb 'will' bear the same implications as presented in the analysis of figures 7 and 8. More importantly, Nigerians who are outraged concerning Boko Haram may see this electioneering material as consoling and hopeful that the APC government is ready to fight and end Boko Haram's reign of terror.

As mentioned earlier, President Buhari is a former military head of state who is now contending for the position of President in a civilian regime. 
It is important to consider why he is referred to as a retired army general in the second poster (Figure 10). On the one hand, this may imply that even though he is retired, he is still experienced enough to deal with the Boko Haram insurgency based on his military background. On the other hand, referring to him as a general implies that as a soldier Buhari has the power to defeat Boko Haram. From a critical perspective, however, this may equally imply that even though he is no longer formal part of the country's military, he has military attributes and experience. Al-Faki (2014) amplifies this when he establishes that linguistic devices used in African political language are not direct, and as a result have hidden agendas which are not easily understood by the general audience.

The attributes of a military dictator are further articulated in the threepoint agenda presented in the electioneering material studied here. Firstly, it is the responsibility of the military to provide maximum security. Secondly, 'zero corruption' is an assertive statement which means that no corruption will be tolerated. Lastly, the military is associated with high levels of discipline, and Buhari will translate this discipline to his mode of governance. This bodes well in instances of propaganda in political language, as discussed by Sharndama (2016). This is an example of Sharndama's card-stacking propaganda, where political communications are permeated with the use of facts or falsehoods, illustrations or distractions and logical or illogical statements in order to present a specific message to the masses. In such cases, words are selected carefully to entice an audience to invest hope in a government. For example, one would find politicians often presenting themselves as a 'God's anointed one', or as a 'Messiah', who can liberate or emancipate the masses.

The sentence: 'Nigeria needs Muhammadu Buhari' in the same material indicates Buhari as a saviour of the Nigerian people, especially in terms of the points listed. It can be argued that there is a type of 'messianic' belief attached to Buhari. The origin of the term 'Messiah' can be attributed to the biblical anointment narratives used to describe a divinely appointed figure who will come at the end of days as a deliverer (Shahar 2018). In other words, and within the context of this study, the 'Messiah' is a leader regarded as the saviour of a country or group. Since this is an objective that cannot be achieved by Buhari alone, he entrusts this power to all Nigerians (Figure 9) through his statement: 'The power to change Nigeria is in your hands'. Sharndama refers to such an instance as a propaganda of integration, where the language of politics is not used against any one person specific, but rather to unite the 
people in a common goal or cause. This could be considered an act of repurposing political messages to make the electorates associate themselves with the beliefs of a specific candidate.

\section{The Aftermath}

The APC reaffirms that their electioneering promises are being achieved (Figures 11 and 12), creating the impression that their administration has already achieved enormous success, evident in statements such as: 'Boko Haram reduced'; 'corruption checkmated'; 'Nigeria's integrity abroad restored'; 'corruption stamped out'; and 'inflation goes down'. These are examples of euphemisms, as explained by Crespo-Fernández (2014) and Hojati (2012: 552).
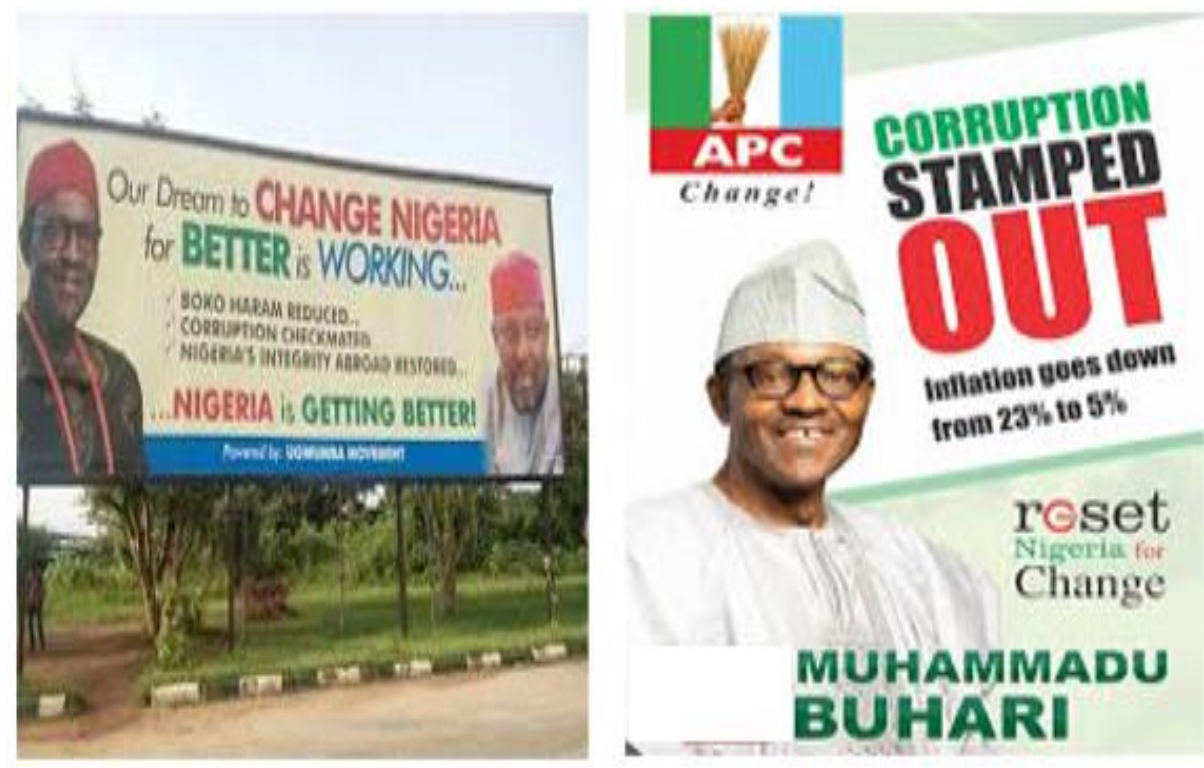

Figures 11, 12: Presenting the aftermath of the elections

Euphemisms are frequently used by speakers of different languages to soften the impact of concepts with the potential to cause offence or provoke social disapproval.

The use of euphemism in political discourse is noted by Crespo- 
Fernández to present a 'safe' way for politicians to deal with unpleasant subjects and criticise their opponents without giving a negative impression to their audiences. In this case, the intention is to prove beyond reasonable doubt that the APC has been able to outperform the PDP by downplaying serious issues in Nigeria. This is also done in a bid to posit the APC as having done enough to return to governance after their current administration. In a way, these political materials are meant to represent the fact that Buhari has achieved, and is still achieving, his mission.

The phrase 'Change Nigeria' (Figure 11) is presented in a red and bold font to catch the attention of the audience. The colour red, in several cultures, has been semiotically perceived to imply danger, or rather to insinuate a phenomenon which requires rapid attention. This further confirms that the APC apparently perceives the situation in Nigeria as dangerous, and as such aims to convince people that the party is there to eradicate such danger. The same graphitic method is employed on the lexical item 'better' presented in a green font. Green is one of the colours in the Nigerian flag, and symbolises Nigeria's natural wealth in its agriculture. In this case, the impression given by using a green font is that the 'better' state of the Nigerian situation can still progress further to be the 'best'.

Terminology related to chess is deliberately used in the phrase: 'Corruption Checkmated'. The word, 'checkmate', is again used to repurpose, recycle and re-contextualise language, as explained by Bakhtin (1986). Checkmate is a position in chess whereby a player's king is about to be captured and there is no possibility of removing the threat.

The hidden meaning is that corruption has been defeated, a fact which is highly contested. This is similar to Fairclough's (2003: 40) view that texts inevitably make assumptions; in other words, 'what is 'said' in a text is 'said' against a background of what is 'unsaid' but taken as given'. Bakhtin (1986) presents the valid point that contexts are dynamic, and thus only become relevant through interaction. As such, discourse is gradually appropriated over time, and often made more relevant in new situations by being re-contextualised and accommodated in new communicative projects.

In all the materials analysed above, the symbol of the APC is present. This advocates the brand identity of the party for people to easily relate to as a mode of identification with the APC. Ademilokun and Olateju (2015) recognise political signifiers as tools for political expression. People arguably easily associate with brands, and such associations guide their perspectives. 


\section{Conclusion}

This study has presented misrepresentative and manipulative practices in the powerplay of Nigerian politicians as exhibited by the APC. This was executed in accordance with supporting literature substantiating the power present in political discourse. MDA was mainly employed to analyse visuals in terms of images and symbolic representations. As such, graphic representations were analysed in accordance with their suggested meaning within a political environment. It has become evident that power resides within discourse, and as such discourse can be used to achieve several goals, such as manipulating audiences and misrepresenting facts to achieve political purposes. As indicated with the analysis and pursuing discussion, different themes contribute to powerplay in Nigerian politics.

The APC backgrounds their campaigns against insecurity issues and concerns of corruption. The party portrays their flagbearer, President Muhammadu Buhari, as a saviour, and as the figurative Biblical Moses, intending to lead the nation to the promised land. In some instances, President Buhari is portrayed as a man of integrity, which is a response to the corrupt situation in the country. This sends a strong message to the masses that corruption will be outrooted in Nigeria if President Buhari is voted in as the country's President. This message is further enforced by the content of discourses which show how the APC administration has seemingly already excelled. The occurrence of words such as 'corruption', 'insecurity', 'integrity' and 'trust' are evident in current Nigerian political discourse and implied in Nigerian governance, and are regarded as important factors in the powerplay of Nigerian politicians.

\section{References}

Ademilokun, M. \& M. Olateju 2015. A Multimodal Discourse Analysis of Some Newspaper Political Campaign Advertisements for Nigeria's 2015 Elections. International Journal of Society, Culture and Language 1: 1 19.

Ademilokun, M. \& R. Taiwo 2013. Discursive Strategies in Newspaper Campaign Advertisements for Nigeria's 2011 Elections. Discourse and Communication 7,4: 435-455. https://doi.org/10.1177/1750481313494501 
Kunle Oparinde, Maleshoane Rapeane-Mathonsi \& Gift Mheta

Ademilokun, M. 2016. Appraisal of Resources in Post-election Defeatconcession Speeches of Some Gubernatorial Candidates in Southwestern Nigeria, 2014 - 2015. Africology: The Journal of Pan African Studies 9,1: $167-187$.

Africa Check 2014. Is President Jonathan Right to Say Most Corruption is Just 'Common Stealing'? Available at:

https://africacheck.org/reports/is-president-jonathan-right-to-claim-mostcorruption-is-just-common-stealing/

Al-Faki, I.M. 2014. Political Speeches of Some African Leaders from Linguistic Perspective (1981 - 2013). International Journal of Humanities and Social Science 4,3: 180 - 198.

Bakhtin, M.M. 1986. Speech Genres and Other Late Essays. Texas: University of Texas Press.

Cabrejas-Peñuelas, A.B. 2015. Manipulation in Spanish and American preelection Political Debates: The Rajoy - Rubalcaba vs. Obama - McCain debates. Intercultural Pragmatics 12,4: 515 - 546.

https://doi.org/10.1515/ip-2015-0025

Cameron, D. \& I. Panovic 2014. Working with Written Discourse. London:

SAGE Publications Ltd.

https://doi.org/10.4135/9781473921917

Chikileva, L.S. 2018. Presidential Political Discourse as a Means of Manipulation: A Pragma Linguistic Aspect. Liberal Arts in Russia 7,1: 20 $-29$.

https://doi.org/10.15643/libartrus-2018.1.3

Crespo-Fernández, E. 2014. Euphemism and Political Discourse in the British Regional Press. Brno Studies in English 40,1: 1 - 19.

https://doi.org/10.5817/BSE2014-1-1

Davletbaeva, D.N., M.E. Yashina \& A.D. Sharafieva 2016. Linguistic Peculiarities of the Modern Political Discourse of Russia and the USA. Journal of Organizational Culture, Communications and Conflict 20, Supplement: 242 - 247.

Ehineni, T.O. 2014. A Critical Discourse Analysis of Models in Nigerian Political Manifestos. International Journal of Linguistics 6,3: 109 - 117. https://doi.org/10.5296/ijl.v6i3.5589

Elebute, A. 2013. The Tradition of Marketing Nigeria Politicians through Visual Media. International Journal of Arts and Humanities 2,2: 255 269. 
Emeka-Nwobia, N.U. 2016. Political Manipulation in Nigerian Presidential Discourses. British Journal of English Linguistics 4,4: 12 - 23.

https://doi.org/10.4314/laligens.v4i1.2

Fairclough, N. 2003. Analysing Discourse: Textual Analysis for Social Research. London: Routledge.

https://doi.org/10.4324/9780203697078

Foucault, M. 1972. The Archaeology of Knowledge and the Discourse on Language. Pantheon Books: New York.

Hojati, A. 2012. A Study of Euphemisms in the Context of English-speaking Media. International Journal of Linguistics 4,4: 552 - 562.

https://doi.org/10.5296/ijl.v4i4.2933

Ike-Nwafor, N.G. 2015. Critical Discourse Analysis of Selected Political Campaign Speeches of Gubernatorial Candidates in South-Western Nigeria 2007 - 2014. PhD Thesis, University of Nigeria.

Jones, R.H. 2012. Discourse Analysis: A Resource Book for Students. London: Routledge.

Kress, G. \& T. van Leeuwen 1996. Reading Images: The Grammar of Visual Design. London: Routledge.

Lazović, V. 2014. The Language of Online Bank Advertisements in English. Journal of English for Specific Purposes at Tertiary Level 2,1: 88 - 104.

Li, D. 2016. Multimodal Discourse Analysis of the Interpersonal Meaning of TV Advertisements. International Journal of Social Science and Humanity 6,12: 934 - 938.

https://doi.org/10.18178/ijssh.2016.V6.776

Lirola, M.M. 2016. Multimodal Analysis of a Sample of Political Posters in Ireland during and after the Celtic Tiger. Revista Signos Estudios De Lingüística, 245 - 267.

https://doi.org/10.4067/S0718-09342016000200005

Liu, J. 2013. Visual Images' Interpretive Strategies in Multimodal Texts. Journal of Language Teaching and Research 4,6: 1259 - 1263. https://doi.org/10.4304/jltr.4.6.1259-1263

Maalej, Z.A. 2013. Framing and Manipulation of Person Deixis in Hosni Mubarak's Last Three Speeches: A Cognitive Pragmatic Approach. Pragmatics 23,4: 633 - 659.

https://doi.org/10.1075/prag.23.4.03maa

Machin, D. 2007. Introduction to Multimodal Analysis. London: Oxford University Press. 
Kunle Oparinde, Maleshoane Rapeane-Mathonsi \& Gift Mheta

Michira, J.N. 2014. The Language of Politics: A CDA of the 2013 Kenyan Presidential Campaign Discourse. International Journal of Education and Research 2,1: 1-18.

Mocanu, M. 2015. The Identity of the Political Language Compared to Other

Types of Language. International Letters of Social and Humanistic

Sciences 45: 35 - 46.

https://doi.org/10.18052/www.scipress.com/ILSHS.45.35

Norris, S. 2016. Concepts in Multimodal Discourse Analysis with Examples from Video Conferencing. Yearbook of the Poznan Linguistic Meeting 2: $141-165$.

https://doi.org/10.1515/yplm-2016-0007

Ogbeidi, M. 2012. Political Leadership and Corruption in Nigeria since 1960:

A Socio-economic Analysis. Journal of Nigeria Studies 1,2: 1 - 25.

Oparinde, K.M. 2018. A Critical Deconstruction of Political Discourse and

Symbols: The Case of (mis)Representation and Manipulation in Nigerian

Politics. PhD Dissertation. Durban University of Technology, South Africa.

Paul, O.U., O. Albert \& A.S. Adeiza 2015. Electricity Crisis in Nigeria: The Way Forward. American Journal of Renewable and Sustainable Energy 1,4: 180 - 186.

Rigotti, E. 2005. Towards a Typology of Manipulative Processes. In de Saussure, L. \& P. Schulz (eds.) Manipulation and Ideologies in the

Twentieth Century: Discourse, Language, Mind. Amsterdam: John Benjamins. https://doi.org/10.1075/dapsac.17.05rig

Roberts, Z. 2017. Dialogicality in selected Nando's Television Advertisements:

A Multisemiotic Approach. Master's Thesis. University of Western Cape, South Africa.

Rose, J. \& P.M. Heywood 2013. Political Science Approaches to Integrity and Corruption. Human Affairs 23: 148 - 159.

https://doi.org/10.2478/s13374-013-0116-6

Shahar, M.B. 2018. 'Anointed' and 'Messiah': A New Investigation into an Old Problem. Journal for the Study of the Old Testament 42,4: 393 - 413. https://doi.org/10.1177/0309089216677672

Sharndama, E.C. 2016. Discursive Strategies in Political Speech: A Critical Discourse Analysis of Selected Inaugural Speeches of the 2015 Nigeria's Gubernatorial Inaugurals. European Journal of English Language, Linguistics and Literature 3,2: 15 - 28. 
Tepavčević, M. 2014. Political Discourse - A Syntactic and Semantic Analysis. Journal of Interdisciplinary Approaches to Text 1,1: 93 - 120. Van Leeuwen, T. 2005. Introducing Social Semiotics. USA: Routledge. https://doi.org/10.4324/9780203647028

Kunle Oparinde Department of Media, Language and Communication Faculty of Arts and Design Durban University of Technology kunleoparinde123@gmail.com

Maleshoane Rapeane-Mathonsi Faculty of Arts and Design Research Office Faculty of Arts and Design Durban University of Technology maleshoaner@dut.ac.za

Gift Mheta Writing Centre Durban University of Technology giftm@dut.ac.za 